\title{
MODELING AND COST ESTIMATION OF ENERGY PRODUCTION FROM SLUDGE
}

\author{
Arsalan Alavian \\ *Mohammad-Hossein Sarrafzadeh \\ Rahmat Sotudeh-Gharebagh \\ UNESCO Chair in Water Reuse, School of Chemical Engineering, College of \\ Engineering, University of Tehran, Tehran, Iran \\ *(E-mail: Sarrafzdh@ut.ac.ir)
}

\begin{abstract}
Energy recovery from sewage sludge offers an opportunity for sustainable management of sewage sludge and energy. Anaerobic digestion and pyrolysis are among the most promising processes applicable for sewage sludge-to-energy conversion. Anaerobic digestion of sewage sludge forms methane-rich biogas, which can be utilized as fuel to offset heat and electricity consumption of the wastewater treatment sector. However, the digestion process has the efficiency limitation since it cannot sufficiently extract the energy from sewage sludge. The digested sludge is still energy profitable and it contains considerable organic matter, but poor in biodegradability. This paper presents a brief overview of anaerobic digestion, pyrolysis, and the combination of other processes with anaerobic digestion in the application to bio energy production from sewage sludge. An assessment of energy conversion of five sludge to energy pathways is also presented. The pathways via pyrolysis and the combination of anaerobic digestion, thermal hydrolysis, and thermal drying could achieve higher energy efficiency compared to other pathways.
\end{abstract}

\section{KEYWORDS}

Biofuel production; cost effective process; energy efficiency; sludge management; wastewater treatment

\section{INTRODUCTION}

Sewage sludge has been used as a fertilizer in many areas all over the world; however, it can also contribute in solving a number of problems of energy supply and healthy advantage of being a renewable energy source [1]. The production rate of sewage sludge is significant, for instance, nearly 1 million $\mathrm{m}^{3}$ /year of sewage sludge dry solids are produced in the UK [1], 4.2 million $\mathrm{m}^{3} /$ year in Switzerland, and 50 million $\mathrm{m}^{3} /$ year in Germany. Therefore, this massive energy source could be utilized by different technologies. Some of them have been used to extract energy from sewage sludge, including anaerobic digestion, pyrolysis, gasification, and hydrothermal carbonization. Although anaerobic digestion (AD) is thought of as one of the most technically mature and cost effective processes to convert sludge to methane-rich biogas, 
the digested sludge as a byproduct of the process still has energy content which could be harnessed by several procedures such as pyrolysis and thermal drying. The objective of this paper is to present several processes to estimate the energy recovery and compare the results. A comparison between several processes has been made and these are listed below:

1. Conventional $\mathrm{AD}$ and land recycling of the digestate to agriculture [2].

2. Thermal hydrolysis process (THP), AD, and land recycling of the digestate to agriculture [2].

3. THP, AD, and sludge drying for fuel [2].

4. TH pretreatment and sludge drying for fuel [3].

5. Pyrolysis [4].

Application of THP improves the financial and environmental performance compared with conventional $\mathrm{AD}$. The $\mathrm{AD}$ process with drying options and pyrolysis which were used to create a solid fuel were the most sustainable solution economically and environmentally. This study compared economic and environmental effects of these five technology configurations.

\section{ANAEROBIC DIGESTION}

Currently the most widely used method of sludge treatment is AD which could be divided into three different temperature ranges, known as psychrophilic (ambient temperature), mesophilic $\left(30-38^{\circ} \mathrm{C}\right)$ and thermophilic $\left(50-57^{\circ} \mathrm{C}\right)[5]$. The mesophilic process consistently remains dominant in practical application, principally because of its combined benefits with acceptable energy consumption, reliable process operation and favorable process performance (e.g. sludge reduction and bio-gas generation) [6, 7]. In a typical process, sludge is thickened then heated to $35-40^{\circ} \mathrm{C}$ before entering the mixed digester tank, the retention times range from 12 to 30 days. The final digested is then dewatered to a cake and transported off site, for recycling on agricultural land [8]. Figure 1 shows the energy flow for a typical AD configuration.

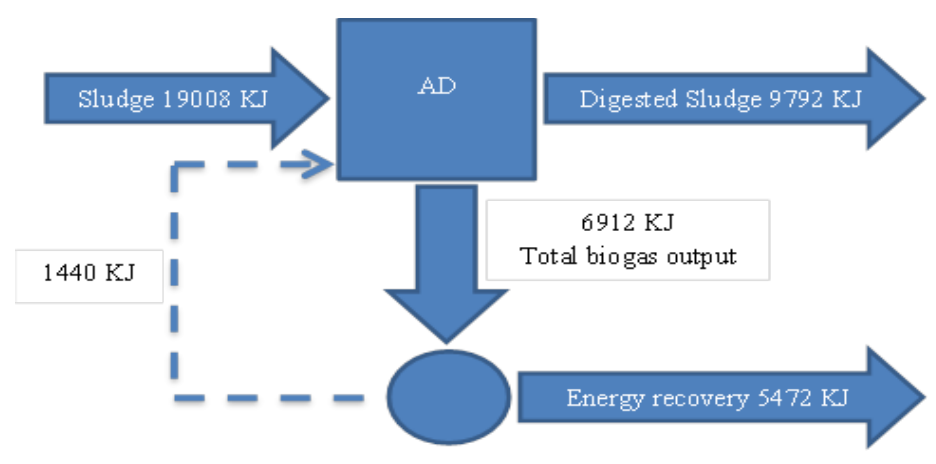

Figure 1. Energy flows for conventional AD (1Kg dry solid/h) [2] 


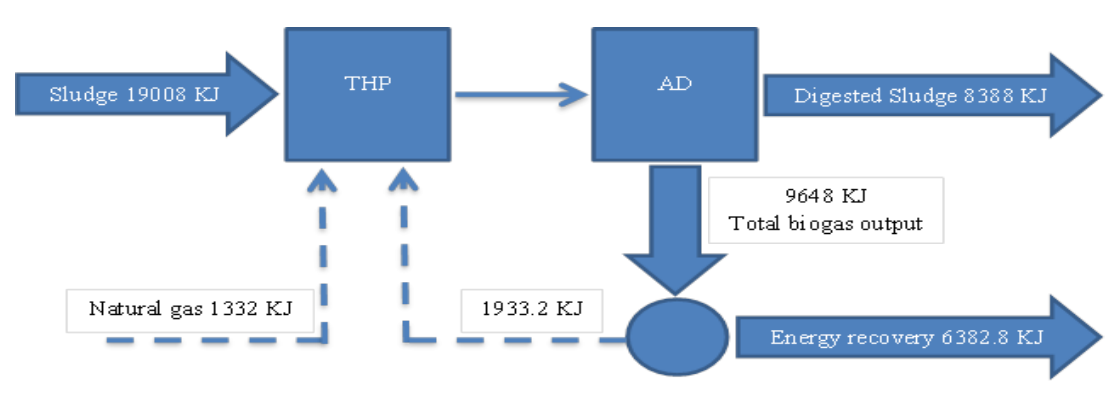

Figure 2. Energy flows for $A D$ and THP (1Kg dry solid/h) [2]

\section{THERMAL HYDROLYSIS PROCESS AND ANAEROBIC DIGESTION}

Anaerobic digestion installations have poor energy recovery and require large assets. Therefore, thermal hydrolysis process (THP) has been developed to improve the digestibility of sewage sludge, increasing methane production in AD, energy efficiency, and operating cost. However, the increase in biogas yield because of the combination of AD and TH processes does not necessarily result in an overall net increase in energy per digested sludge. Figure 2 shows the energy flow for a typical configuration.

\section{THERMAL HYDROLYSIS PROCESS, ANAEROBIC DIGESTION AND SLUDGE DRYING}

To access the considerable chemical energy remaining in the sludge after $A D$, the sludge can either be burnt or be dried to produce a solid fuel product $[9,10]$. The thermal drying process is the most energy-intensive one during the biofuel production, accounting for about $70 \%$ of the total energy consumption $[11,12]$. Thus, one of the efficient ways to save energy is to remove more water from the sludge during the $\mathrm{TH}$ and $\mathrm{AD}$ processes. High heat value of the solid fuel could prove the fact that the combination of these processes could be cost effective.

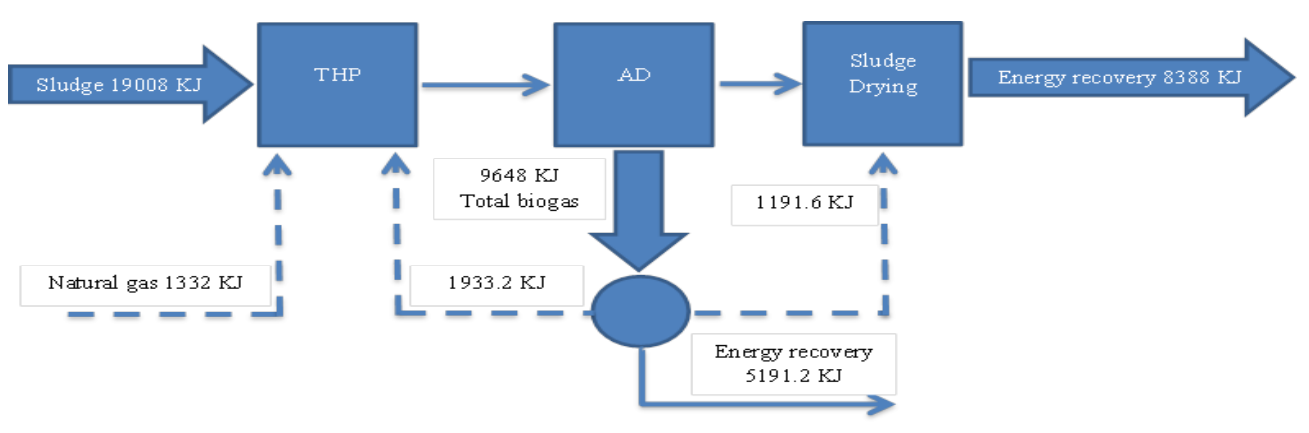

Figure 3. Energy flows for AD, THP and sludge drying (1Kg dry solid/h) [2] 


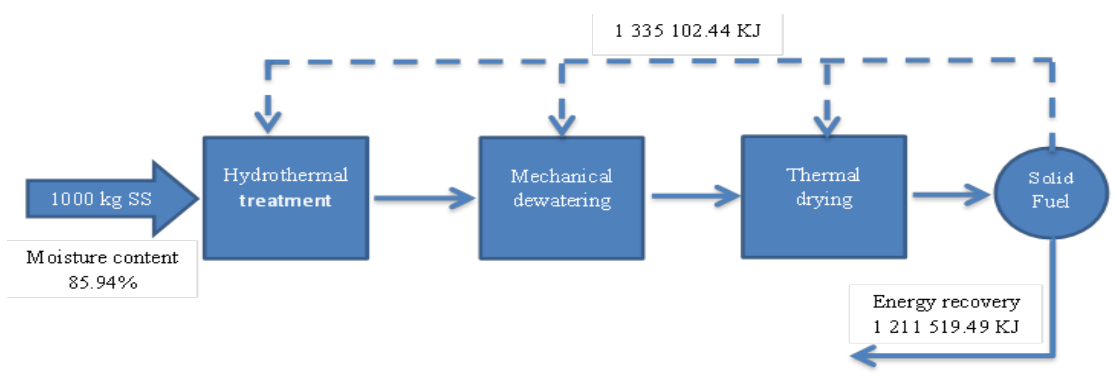

Figure 4. Energy flows for HTP and sludge drying (capacity 1t/batch, $30 \mathrm{~min}$ ) [3]

\section{THERMAL HYDROLYSIS AND SLUDGE DRYING}

The hydrothermal (HT) conversion has bright perspective with three main merits: (1) largely improving the dewaterability; (2) dramatically reduction in volume, especially for the municipal solid waste (MSW); (3) energy densification. Energy contents of the solid biofuel from primary sludge carbonized at $140-200^{\circ} \mathrm{C}$ for $4 \mathrm{~h}$ ranged from 21.5 to $23.31 \mathrm{MJ} / \mathrm{kg}$, and kept increasing with carbonization [13]. Figure 4 illustrates an energy balance of the proposed process (capacity 1t/batch) producing solid biofuel under a temperature of $200^{\circ} \mathrm{C}$ and holding time of $30 \mathrm{~min}$. it clearly shows that the HT pretreatment could be used to produce solid biofuel to recover energy from high moist sewage sludge.

\section{PYROLYSIS}

The pyrolysis plant shown in Figure 5 is concerned with bio-oil produced by fast pyrolysis of biomass. The heart of the system is a bubbling fluidized bed which is indirectly heated to $500^{\circ} \mathrm{C}$ by exhaust gases from a combustor that burns pyrolysis gas and some of the byproduct char [14]. The pyrolysis products (fine particles of solid char, vapors, aerosols, and gasses) leave the reactor with the circulating gas. The char is removed by one or more cyclone separators. The remaining pyrolysis products are then quenched with cool bio-oil which condenses the vapors to form bio-oil. Then the non-condensable gases are blown back into the reactor as fluidizing gases for the fluidized bed.

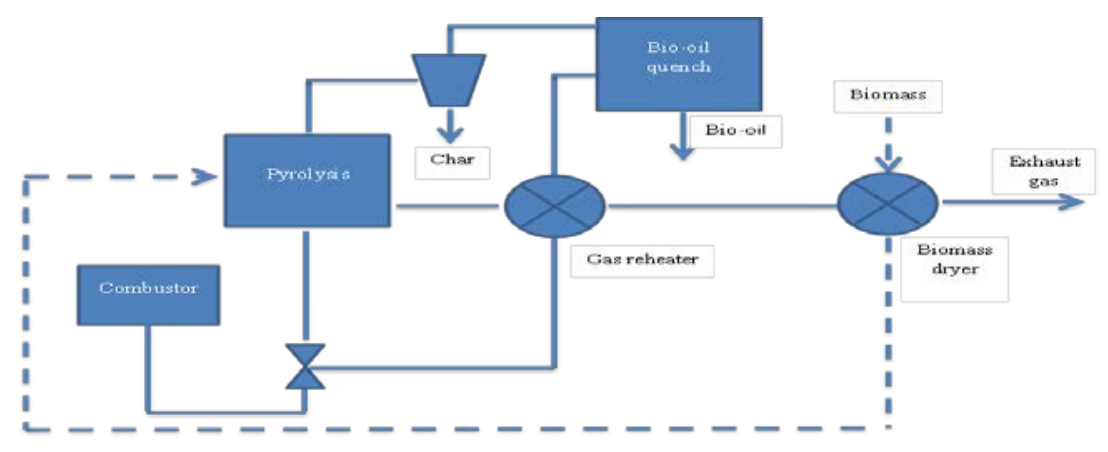

Figure 5. Pyrolysis [4] 


\section{COMPARISON OF ALL ENERGY FLOW PATHWAYS}

Figs1-5 display the summary diagrams for the energy flows in each scenario (note that electricity, road fuel and consumables are not shown but included in the results). Table 1 and Table 2 show all the input and output energy results in more detail. Recovery ratio $\alpha$ is defined as the ratio of the gross energy recovered to total energy generated from the plant. The energy generated from the plant could be in the form of bio oil, bio solid, and bio gas. $\alpha$ ratio could be used as one of the main parameters to compare the energy consumption of the processes. The energy recovery also is defined as the total energy content of all kinds of bio fuels which has been subtracted from total energy consumption of the process such as electricity and thermal requirement.

Table 2 shows the energy consumption and generation of the 5 processes. Based on the data of the table the processes with thermal drying have the highest level of energy input around $9000 \mathrm{KJ} / \mathrm{Kg}$. because of this intense increase in energy consumption of the process, THP sludge drying process has the lowest energy recovery ratio $47 \%$ among the other processes. Table 1 illustrates that Conventional anaerobic digestion (AD) has the lowest energy content because there is no pretreatment and the digestate will be disposed without using its energy. As a result, although THP demands an input of high grade heat and additional electrical energy, when compared with conventional AD, using a thermal hydrolysis (THP) as pretreatment sludge processing could increase the energy content of AD by $17 \%$. To access the considerable chemical energy remaining in the digested sludge, the sludge could be dried to produce a solid fuel product [9]. The use of this process could result in $60 \%$ rise in energy recovery which is considerable. The pyrolysis process is optimized to produce the maximum liquid yield which has the highest calorific value (CV) around 19-23 $\mathrm{MJ} / \mathrm{Kg}$ [15] in comparison with the other products and it is the main reason that the energy recovery of the process is $14800 \mathrm{KJ} / \mathrm{Kg}$. Though the electricity consumption of pyrolysis plants is significant and needs to be considered, the process seems to be feasible in larger capacities.

Table 1. Evaluation of energy recovery from fuel production for $1 \mathrm{~kg}$ dry solid feed

\begin{tabular}{ccc}
\hline Process Type & Energy Recovery & $\alpha$, Recovery Ratio (\%) \\
\hline AD & KJ & 79 \\
THP,AD & 5472 & 66 \\
THP,AD, sludge drying & 6382.8 & 75 \\
THP, sludge drying & 13579.2 & 47 \\
pyrolysis & 8616.78 & 74 \\
\hline
\end{tabular}


Table 2. Results of energy analysis for the pathways for $1 \mathrm{~kg}$ dry solid feed

\begin{tabular}{|c|c|c|c|c|c|c|}
\hline Energy & units & $\mathrm{AD}$ & THP, AD & $\begin{array}{l}\text { THP, } \\
\text { AD, } \\
\text { sludge } \\
\text { drying }\end{array}$ & $\begin{array}{l}\text { THP, } \\
\text { sludge } \\
\text { drying }\end{array}$ & pyrolysis \\
\hline \multicolumn{7}{|l|}{ INPUTS } \\
\hline Electricity & $\mathrm{KJ}$ & 486 & 644.4 & 756 & - & 864 \\
\hline $\begin{array}{l}\text { Natural gas } \\
\text { and thermal } \\
\text { requirement }\end{array}$ & $\mathrm{KJ}$ & - & 1332 & 1332 & 9495.7 & 4300 \\
\hline \multicolumn{7}{|l|}{ OUTPUTS } \\
\hline Bio gas & $\mathrm{KJ}$ & 6912 & 9648 & 9648 & - & 940 \\
\hline Bio oil & $\mathrm{KJ}$ & - & - & - & - & 13200 \\
\hline $\begin{array}{c}\text { Bio } \\
\text { solid/Char }\end{array}$ & $\mathrm{KJ}$ & - & - & 8388 & 18112.53 & 5900 \\
\hline
\end{tabular}

\section{CONCLUSIONS}

This work focused on the energy balance of biofuel production from sewage sludge (SS) by different processes in order to illustrate the energy efficiency of new technologies. AD is widespread and an effective sludge treatment technique for the water industry and the combination of the other thermal processes with AD could increase the energy recovery of the plant. The study has found that both pyrolysis pathway and ADP with the use of TH pretreatment and sludge drying have the highest level of energy recovery and recovery ratio which could be beneficial to produce bio fuel. It is clear that improving processes and technologies are enabling significant opportunities for further energy recovery from sludge. 


\section{REFERENCES}

[1] Midilli, Adnan, Murat Dogru, Colin R. Howarth, Mike J. Ling, and Teoman Ayhan. 2001. "Combustible Gas Production from Sewage Sludge with a Downdraft Gasifier." Energy Conversion and Management 42 (2): 157-72.

[2] Mills, N., P. Pearce, J. Farrow, R. B. Thorpe, and N. F. Kirkby. 2014. "Environmental \& Economic Life Cycle Assessment of Current \& Future Sewage Sludge to Energy Technologies." Waste Management 34 (1): 185-95.

[3] Zhao, Peitao, Yafei Shen, Shifu Ge, and Kunio Yoshikawa. 2014. "Energy Recycling from Sewage Sludge by Producing Solid Biofuel with Hydrothermal Carbonization." Energy Conversion and Management 78: 815-21.

[4] Rogers, J. G., and J. G. Brammer. 2012. "Estimation of the Production Cost of Fast Pyrolysis Bio-Oil.” Biomass and Bioenergy 36: 208-17.

[5] Massé, D. I., D. Lu, L. Masse, and R. L. Droste. 2000. "Effect of Antibiotics on Psychrophilic Anaerobic Digestion of Swine Manure Slurry in Sequencing Batch Reactors.” Bioresource Technology 75 (3): 205-11.

[6] Zupančič, Gregor Drago, and Milenko Roš. 2003. "Heat and Energy Requirements in Thermophilic Anaerobic Sludge Digestion.” Renewable Energy 28 (14): 2255-67.

[7] Kim, Moonil, Young-Ho Ahn, and R. E. Speece. 2002. "Comparative Process Stability and Efficiency of Anaerobic Digestion; Mesophilic vs. Thermophilic.” Water Research 36 (17): 4369-85.

[8] Suh, Young-Jin, and Patrick Rousseaux. 2002. "An LCA of Alternative Wastewater Sludge Treatment Scenarios.” Resources, Conservation and Recycling 35 (3): 191-200.

[9] Flaga, A. 2005. "Sludge Drying." In Proceedings of Polish-Swedish Seminars, Integration and Optimization of Urban Sanitation Systems. Cracow March, 17-18.

[10] Niu, Dong-jie, Hui Huang, Xiao-hu Dai, and You-cai Zhao. 2013. “Greenhouse Gases Emissions Accounting for Typical Sewage Sludge Digestion with Energy Utilization and Residue Land Application in China.” Waste Management 33 (1): 123-28.

[11] Jiang, ZiLi, DaWei Meng, HongYan Mu, and Kunio Yoshikawa. 2010. "Study on the Hydrothermal Drying Technology of Sewage Sludge.” Science in China Series E: Technological Sciences 53 (1): 160-63.

[12] Namioka, Tomoaki, Yoshiaki MOROHASHI, Ryosuke YAMANE, and Kunio YOSHIKAWA. 2009. "Hydrothermal Treatment of Dewatered Sewage Sludge Cake for Solid Fuel Production." Journal of Environment and Engineering 4 (1): 68-77.

[13] Danso-Boateng, E., R. G. Holdich, G. Shama, A. D. Wheatley, M. Sohail, and S. J. Martin. 2013. "Kinetics of Faecal Biomass Hydrothermal Carbonisation for Hydrochar Production." Applied Energy 111: 351-57.

[14] Bridgwater, A. V., and G. V. C. Peacocke. 2000. "Fast Pyrolysis Processes for Biomass." Renewable and Sustainable Energy Reviews 4 (1): 1-73.

[15] Oasmaa, Anja, Cordner Peacocke, and others. 2001. A Guide to Physical Property Characterisation of Biomass-Derived Fast Pyrolysis Liquids. Technical Research Centre of Finland Espoo. http://www.vtt.fi/inf/pdf/publications/2001/P450.pdf. 